\title{
Enhancement in Elastic Modulus of GFRP Bars by Material Hybridization
}

\author{
Dong-Woo Seo*, Ki-Tae Park, Young-Jun You, Hyeong-Yeol Kim \\ Structural Engineering Research Division, Korea Institute of Construction Technology, Goyang, Republic of Korea \\ Email: ${ }^{*}$ dwseo@kict.re.kr
}

Received August 29, 2013; revised September 29, 2013; accepted October 10, 2013

Copyright (C) 2013 Dong-Woo Seo et al. This is an open access article distributed under the Creative Commons Attribution License, which permits unrestricted use, distribution, and reproduction in any medium, provided the original work is properly cited.

\begin{abstract}
Fiber reinforced polymer (FRP) reinforcing bars for concrete structure has been extensively investigated for last two decades and a number of FRP bars are commercially available. However, one of shortcomings of the existing FRP bars is its low elastic modulus, if glass fibers are used (i.e., GFRP). The main objective of this study using the concept of material hybridization is to develop a viable hybrid FRP bar for concrete structures, especially for marine and port concrete structures. The purposes of hybridization are to increase the elastic modulus of GFRP bar with acceptable tensile strength. Two types of hybrid GFRP bar were considered in the development: GFRP crust with steel core and GFRP bar with steel wires dispersed over the cross-section. Using E-glass fibers and unsaturated polyester resins, the hybrid GFRP bar samples of $13 \mathrm{~mm}$ in diameter were pultruded and tested for tensile properties. The effect of hybridization on tensile properties of GFRP bars was evaluated by comparing the results of tensile test with those of non-hybrid GFRP bars. The results of this study indicated that the elastic modulus of the hybrid GFRP bar was increased by up to 270 percent by the material hybridization. The results of the test and the future recommendations are summarized in this paper. To ensure long-term durability of the hybrid GFRP bars in waterfront structure applications, the individual and combined effects of environmental conditions on hybrid GFRP rebar itself as well as on the interface between rebar and concrete should be accessed.
\end{abstract}

Keywords: FRP; Glass Fibers; Tensile Test; Elastic Modulus; Pultrusion; Material Hybridization; Marine Structures

\section{Introduction}

Fiber Reinforced Polymer (FRP) is widely used as an alternative material to resolve the corrosion problem of the steel reinforcement and to increase the service life of reinforced concrete (RC) structures. FRP rebar can provide high tensile strength as well as good resistance to corrosion comparing to the steel reinforcement [1] for $\mathrm{RC}$ structures, especially ones exposed to corrosive environments such as sea water. However, FRP has not been actively applied as the reinforcement or structural materials in civil engineering structures due to its low elastic modulus and brittle fracture.

FRP is mainly composed of fibers and resin. Glass and carbon are commonly used fiber materials. Carbon fiber provides even higher tensile strength and more elastic modulus than steel. These are advantageous features of using carbon fiber in a structural point of view but not in economics, since its price is almost ten times higher than

\footnotetext{
*Corresponding author.
}

glass fiber. Use of glass fiber can be more beneficial material in the initial cost. However, low modulus of elasticity is a main disadvantage of using glass fiber, which attains the elastic modulus less than a quarter of steel. This leads to excessive deflection when FRP rebar was used as the reinforcement for flexural members. With this reason, the concept of "hybridization" was arisen for the FRP rebar to overcome their shortcomings. The hybridization of FRP has been investigated by many researchers [2-5].

This paper discusses the recent development of FRP hybrid bars using glass fiber and an experimentation of their tensile properties. The purpose of this study is to identify a feasible material hybridization of the glass fiber reinforced polymer (GFRP) reinforcing bar to be used for concrete structures. Two different materials, mainly the combination of fibers and steel within the cross-section of FRP bar, were considered for the hybrid FRP bars. Two types of the hybrid GFRP bar were considered in the development: a) GFRP crust with steel 
core; b) GFRP bar with steel wires dispersed over the cross-section.

GFRP rebar with a circular cross-section was considered. Both vinylester and unsaturated polyester were utilized as resin materials. For comparison purpose, the existing GFRP bar developed and fabricated at Korea Institute of Construction Technology (KICT, [6-8]) and also two commercially available GFRP bars (Aslan and V-rod $[9,10]$ ) were tested. The effect of material hybridization on tensile properties of GFRP bars was evaluated by comparing the results of tensile test with those of the non-hybrid bars.

\section{Development of Hybrid GFRP Bars}

This study suggests two types of hybrid GFRP bars considering in the development: a) GFRP crust with steel core; b) GFRP bar with steel wires dispersed over the cross-section. Using E-glass fibers and unsaturated polyester resins, the hybrid GFRP bar samples of $13 \mathrm{~mm}$ in diameter were pultruded and tested for tensile properties. Figure 1 shows the pultrusion process designed by KICT. Vinylester (VE) and unsaturated polyester (PE) were used as resins.

Table 1 summarizes four cross-section types considered in this study, categorized by steel volume fraction from $0 \%$ to approximately 48\%. Type A (e.g., KICT, Aslan, and V-Rod) was selected as a reference case that was considered as a non-hybrid GFRP bar. For the designing purpose, the tensile strength of the hybrid GFRP bar was assumed to be $800 \mathrm{MPa}$.

For type B, diameter equal to $4 \mathrm{~mm}$ steel bar was inserted with volume fraction $9.5 \%$ in the cross-section. A

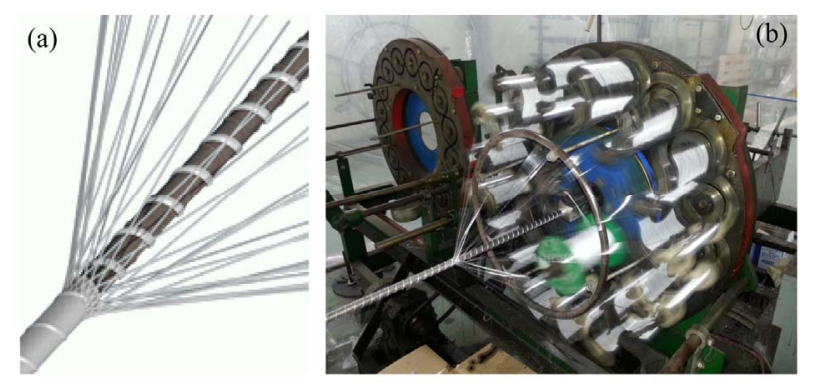

Figure 1. Fabricating method for GFRP hybrid bars [6]: (a) Detailed view of braiding method; (b) Pultrusion process while braiding.

Table 1. Type of FRP hybrid bar samples.

\begin{tabular}{cccccc}
\hline Type & A & B & C & D \\
\hline $\begin{array}{c}\text { Steel volume fraction by } \\
\text { cross-section area (\%) }\end{array}$ & None & 9.5 & 30.8 & \\
Cross-Section & & & & &
\end{tabular}

total of 13 numbers of $2 \mathrm{~mm}$ steel wire were inserted with volume fraction $30.8 \%$ for type C. In case of type D, $9 \mathrm{~mm}$ steel rebar was inserted into GFRP to be an outer diameter equal to $13 \mathrm{~mm}$, steel volume fraction was $47.9 \%$.

The hybrid bars were fabricated with a circular crosssection of diameter equal to approximately $13 \mathrm{~mm}$. Eglass fiber (SE1200-2200TEX, Owens Corning Korea [11]), steel wire (KS D3510 C-type, Korea) and steel rebar (nominal strength with $400 \mathrm{MPa}$ ) were used in this study. Vinylester and unsaturated polyester are known as effective resins for the pultrusion process of fabrication because they offer economical advantage, low viscosity, and rapid hardening. The material properties of the fiber and resins are provided in Table 2.

\section{Experiments}

\subsection{Tensile Test}

The tensile tests on the specimens were carried out in accordance with ASTM D 3916 [12]. The total length of the specimens was $2000 \mathrm{~mm}$ and the gauge length was $1070 \mathrm{~mm}$. An UTM with a capacity of $1000 \mathrm{kN}$ was used. Strain gauges were attached at the center and the quarter of the specimens within the gauge length. The specimens were fixed both at the top and the bottom with steel grip adapters shown in Figure 2. Mortar was filled into the

Table 2. Material properties of fiber and resins [8].

\begin{tabular}{cccc}
\hline Material & $\begin{array}{c}\text { Tensile strength } \\
(\mathrm{MPa})\end{array}$ & $\begin{array}{c}\text { Elastic modulus } \\
(\mathrm{GPa})\end{array}$ & $\begin{array}{c}\text { Elongation } \\
(\%)\end{array}$ \\
\hline E-glass fiber & 2410 & 79.0 & 3.04 \\
Vinylester resin & 9 & 3.7 & 7.00 \\
$\begin{array}{c}\text { Unsaturated } \\
\text { polyester resin } \\
\text { Steel wire }\end{array}$ & 62 & 3.1 & \\
Steel rebar & 16.5 & 200 & \\
\hline
\end{tabular}

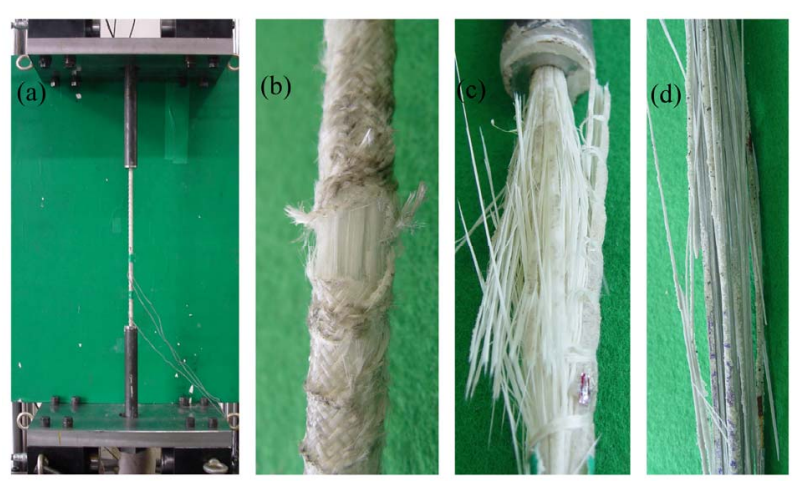

Figure 2. Test setup and fracture types: (a) Tensile test setup; (b) Hybrid GFRP fracture; (c) Aslan fracture; (d) VRod fracture. 
grip adapters and cured for two weeks to obtain the compressive strength approximately $60 \mathrm{MPa}$. Figure 2 shows the tensile test with the loading rate equal to $5 \mathrm{~mm} / \mathrm{min}$ [13].

Brittle fractures of GFRP bars, including Case A, Asaln, and V-rod were seen in Figure 3 one of shortcomings of FRP was a brittle fracture and this issue was improved by material hybridization proved in this study.

Table 3 summarizes the list of specimens that tested in this study. 7 cases of tested specimens were selected for tensile test associated with 4 types explained in Table 1. A total of 21 samples consisting 3 specimens for each case was tested.

Cases A through $\mathrm{C}$ were corresponding to the types $\mathrm{A}$, $\mathrm{B}$, and $\mathrm{C}$ in Table 1. For cases D-1 and D-2, type D in Table 1 was subdivided into two types depending on a steel type; Case D-1 with circular shape of rebar and D-2 with the deformed rebar. Cases A through D-2 were developed and fabricated by KICT [6]. Two commercially available GFRP bars (i.e., Aslan and V-Rod, [9,10]) were also considered and their tensile strength was compared to other hybrid GFRP bars developed at KICT.

\subsection{Results and Discussion}

The tensile strength of the specimen can be calculated by dividing the measured maximum load by the cross-sectional area of the GFRP bar $\left(A_{\text {hybrid }}\right)$. The elastic modulus of the GFRP bar $\left(E_{\text {hybrid }}\right)$ can be given by the following expression as recommended in [13].

$$
E_{\text {hybrid }}=\frac{\left(P_{1}-P_{2}\right)}{\left(\varepsilon_{1}-\varepsilon_{2}\right) A_{\text {hybrid }}} .
$$

In Equation (1) $P_{1}$ and $P_{2}$ are the applied loads corresponding to $50 \%$ and $25 \%$ of the ultimate load respectively, and $\varepsilon_{1}$ and $\varepsilon_{2}$ are the corresponding strains.

Table $\mathbf{4}$ and Figures $\mathbf{3}$ and $\mathbf{4}$ summarize the result of tensile tests. Figure $\mathbf{3}$ shows a linear increment of elastic The linear stress-strain relationship of the specimens was found for Case A, Aslan and V-rod, in which no material hybridization was considered.

In these cases the brittle fracture was occurred shown Figures 1(c) and (d). Small change of the curvature was

Table 3. List of specimens for tensile test.

\begin{tabular}{ll}
\hline Case & Description \\
\hline A & D13 with GFRP only \\
B & D13 with GFRP and D4 steel wire inserted \\
C & D13 with GFRP and D2 × 13EA (steel wire) inserted \\
D-1 & D13 with GFRP and D9 rebar inserted \\
D-2 & D13 with GFRP and D9 deformed rebar inserted \\
Aslan & D13 Aslan 100 [9] \\
V-Rod & D13 V-Rod GFRP [10] \\
\hline
\end{tabular}

Table 4. Results of tensile tests at the location $L / 2$.

\begin{tabular}{ccccc}
\hline \multirow{2}{*}{ Case } & \multicolumn{2}{c}{ Elastic Modulus $(E)$} & \multicolumn{2}{c}{ Tensile Strength $(P)$} \\
\cline { 2 - 5 } & GPa & $\mathrm{N}(E)$ & MPa & $\mathrm{N}(P)$ \\
\hline A & 49.6 & 1.00 & 754.4 & 1.00 \\
B & 53.7 & 1.08 & 762.1 & 0.94 \\
C & 98.3 & 1.98 & 688.2 & 0.85 \\
D-1 & 129.2 & 2.60 & - & - \\
D-2 & 133.2 & 2.69 & 715.4 & 0.88 \\
Aslan & 52.5 & 1.06 & 601.8 & 0.74 \\
V-Rod & 46.2 & 0.93 & 574.6 & 0.71 \\
\hline
\end{tabular}

found for cases B and C after steel wire was likely yielded earlier than GFRP. The bilinear type of fracture behavior was detected for cases D-1 and D-2. In these cases, failure mechanism is clearly dominated by steel rebar in the initial stage and GFRP holds the applying loads after approximately $350 \mathrm{MPa}$.

Most of the specimens failed in the gauge length, but some of them presented ruptures at the grip adapters. The averaged value of the three specimens for each case results, measured at the location $L / 2$, was presented in Table 4. A negligible difference of strains between the two locations, $L / 2$ and $L / 4$, was found. In Table 4, values for both elastic modulus $(E)$ and maximum tensile strength $(P)$ were normalized to case A for comparison purpose. Case A was considered as a non-hybrid GFRP bar developed at KICT.

Enhancement in elastic modulus was investigated by material hybridization up to $269 \%$. However, regarding the tensile strength, a small reduction was found for all cases. This reduction may occur due to damage, the size of specimen, the gripping method, or slip between two materials (i.e., GFRP and steel). More detailed study for this issue is planned by the authors.

Cases D-1 and D-2 shows the highest hybrid effect for the GFRP bar in terms of elastic modulus with steel fraction of $47.9 \%$.

The commercial GFRP bars, Aslan and V-Rod provided maximum tensile strength approximately 30\% lower than "KICT GFRP bar" while elastic modulus was a similar value supposed to be around $50 \mathrm{GPa}$.

\section{Conclusions}

In this study material hybridization of GFRP bar was considered to overcome its low elastic modulus to be used as reinforcement for concrete structures built in the corrosive environment. The existing GFRP bar developed at Korea Institute of Construction Technology (KICT [6]) was hybridized by adding steel as a high strength material. Various combinations of mixing ratio between GFRP and steel were investigated. 


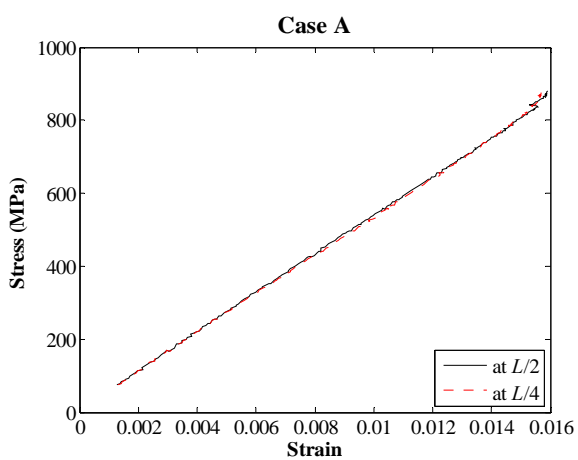

(a)

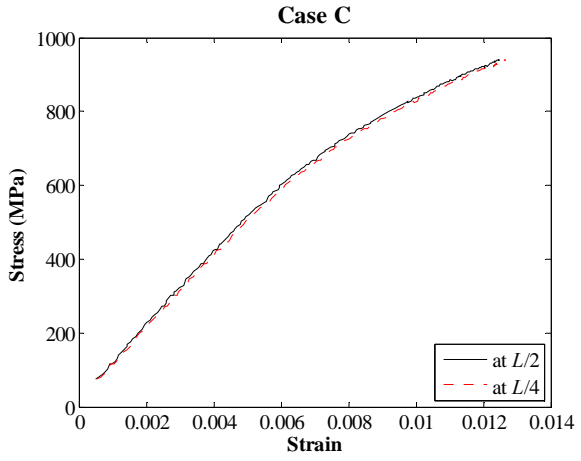

(c)

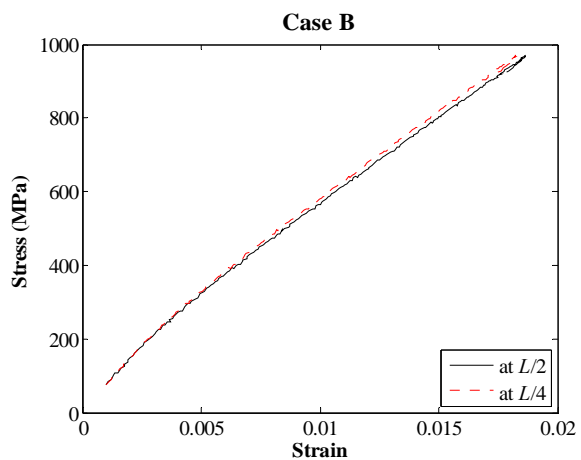

(b)

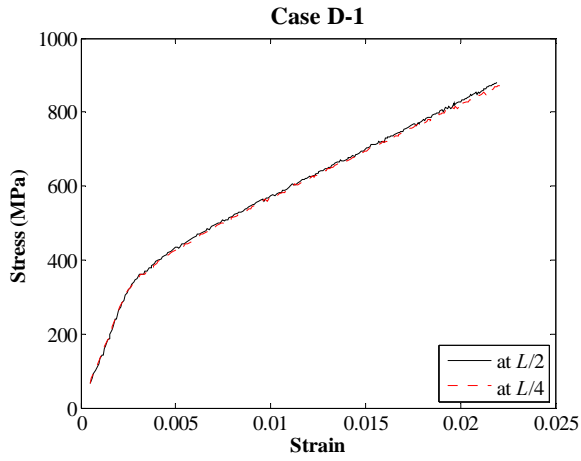

(d)

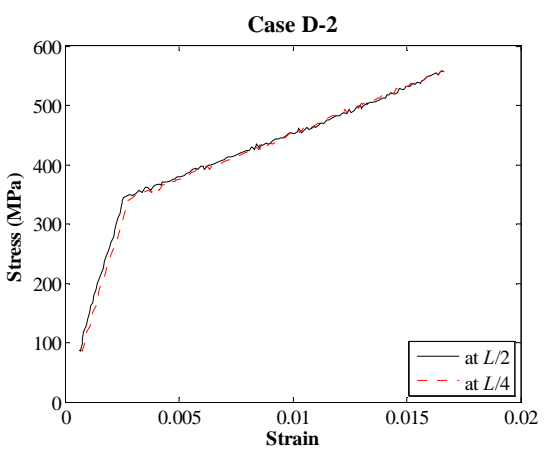

(e)

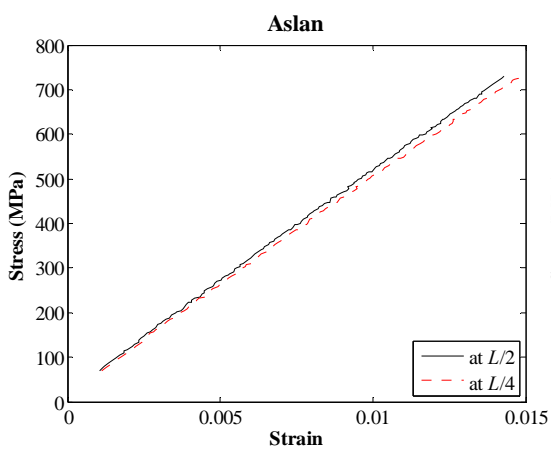

(f)

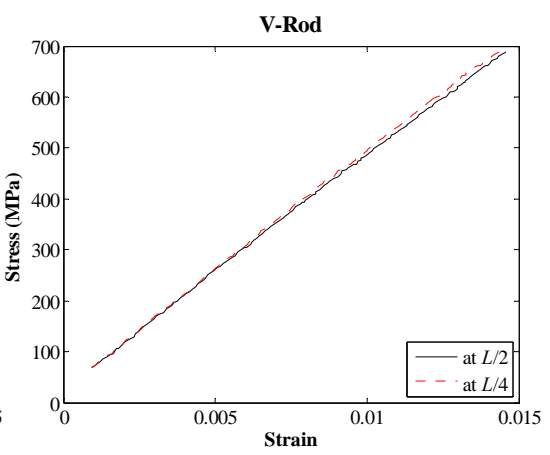

(g)

Figure 3. Stress vs. strain curves at the location $L / 2$ and $L / 4$ for hybrid GFRP specimens: (a) Case A; (b) Case B; (c) Case C; (d) Case D-1; (e) Case D-2; (f) Aslan; (g) V-Rod.

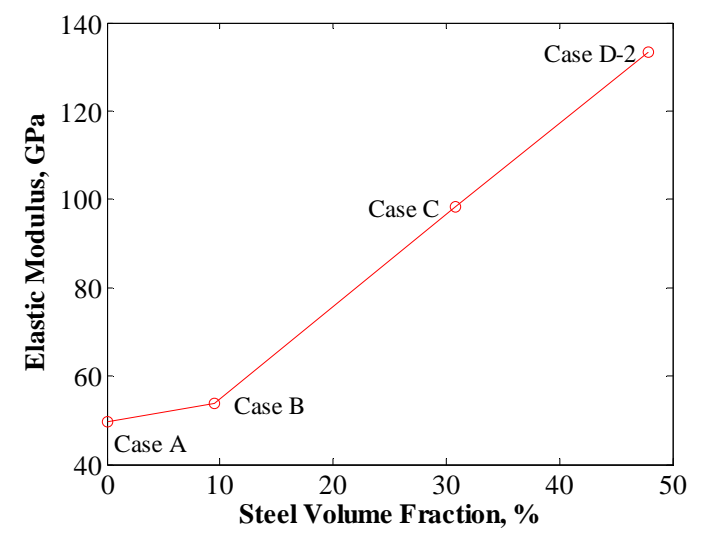

Figure 4. Relationship between steel volume fraction in the cross-section and elastic modulus.
As a result of tensile test, the elastic modulus of the hybrid rods was increased by $8 \%$ to $269 \%$ with material hybridization in comparison with the non-hybrid GFRP bar. However, a small reduction of tensile strength was found. This reduction may occur due to damage, misplacement of fibers during the fabrication, the size of specimen, the gripping method, or slip between two materials (i.e., GFRP and steel). More detailed study for this issue is planned by the authors.

One of shortcomings of FRP was a brittle fracture and this issue was improved to "pseudo-ductile" behavior by material hybridization.

The hybrid effect was the largest where steel was added the most in the section. Furthermore, the increment of elastic modulus was proportional to the quantity 
of steel added in the section.

Further investigation should be conducted to study the effect of the stress redistribution mechanism on the "pseudo-ductile" behavior regarding to the quantity as well as the dispersion of steel. Economic feasibility of the hybrid FRP bars should also be investigated.

\section{Acknowledgements}

This research (2013 Basic Research: Development of Hybrid FRP Bars for Concrete Waterfront Structures) was supported by Korea Institute of Construction Technology and funded by the Ministry of Science, ICT, and Future Planning of Korean Government.

\section{REFERENCES}

[1] A. A. Mufti, M.-A. Erki and L. G. Jaeger, "Advanced Composites Materials with Application to Bridges," Canadian Society of Civil Engineers, Montreal, 1991.

[2] G. Kretsis, "A Review of the Tensile, Compressive, Flexural and Shear Properties of Hybrid Fibre-Reinforced Plastics,” Composites, Vol. 18, No. 1, 1987, pp. 13-23. http://dx.doi.org/10.1016/0010-4361(87)90003-6

[3] K. D. Jones, A. T. Di Benedetto, "Fiber Fracture in Hybrid Composite Systems," Composites Science and Technology, Vol. 51, No. 1, 1994, pp. 53-62. http://dx.doi.org/10.1016/0266-3538(94)90156-2
[4] C. E. Bakis, A. Nanni, J. A. Terosky and S. W. Koehler, "Self-Monitoring, Pseudo-Ductile, Hybrid FRP Reinforcement Rods for Concrete Applications," Composites Science and Technology, Vol. 61, No. 6, 2001, pp. 815823. http://dx.doi.org/10.1016/S0266-3538(00)00184-6

[5] L. Taerwe, "Non-Metallic FRP Reinforcement for Concrete Structures: Proceedings of the Second International Rilem Symposium,” Taylor \& Francis, London, 1995.

[6] Korea Institute of Construction Technology (KICT). www.kict.re.kr

[7] Korea Institure of Construction Technology (KICT), "Design and Construction Technology for Concrete Structures Using Advanced Composite Materials: FRP Rebars and Grids (in Korean),” Korea Research Council of Public Science and Technology, Interim Report, 2004.

[8] Y.-J. You, Y.-H. Park, H.-Y. Kim and J.-S. Park, "Hybrid Effect on Tensile Properties of FRP Rods with Various Material Compositions," Composite Structures, Vol. 80, No. 1, 2007, pp. 117-122. http://dx.doi.org/10.1016/j.compstruct.2006.04.065

[9] ASLAN. www.aslanfrp.com

[10] V-Rod. www.vrod.ca

[11] Owens Corning. http://www.owenscorning.co.kr/

[12] ASTM. D 3916, “Standard Test Method for Tensile Properties of Pultruded Glass-Fiber-Reinforced Plastic Rods," 2002.

[13] CSA, "Test Method for Tensile Properties of FRP Reinforcement,” Canadian Standard Association, 2002. 